\title{
COOPERATIVISMO NO MERCADO INFORMACIONAL DO MERCOSUL: UMA ALTERNATIVA
}

\author{
Fátima Maria Alencar Araripe \\ Rossana Coely de Oliveira Moura
}

\begin{abstract}
Resumo
O texto enfoca o cenário atual do processo de globalização como o grande propulsor do desencadeamento das preocupações das nações em formar alianças por blocos econômicos. Apresenta a globalização como um coadjuvante do fator desemprego e aponta o cooperativismo como uma alternativa de trabalho no mercado da informação. Nesse contexto, ressalta a importância das bases informacionais como pressuposto básico para a adequação dos produtos e serviços que atendam a essa nova ordem social.
\end{abstract}

\section{Palavras-Chave}

Globalização; informação; Mercosul; cooperativismo.
As últimas décadas do término deste milênio está, notadamente, marcada pela

"E a informação existe sempre, até mesmo na ausência de produtos de informação."

Michel J. Menou acentuada abertura de mercado em todos os âmbitos do fazer social. Vemos seus sinais por todos os lados, na mídia, na política, na cultura, na ciência, na informação e, principalmente e objetivamente, na economia. A esse grande movimento que embala 
a tudo e a todos, e que interfere nos sistemas de relação e sociabilidade, denominamos de globalização.

A globalização, como um processo antigo, se levarmos em conta as trocas de produtos e conhecimentos, ou como um fenômeno emergente se atribuírmos à globalização a produção, distribuição e consumo de bens e serviços, organizados a partir de uma estratégia mundial com vistas em um mercado mundial.

Cremos, na verdade, podermos considerar a premissa primeira como indícios de globalização. No entanto, nossa atenção estará mais voltada para esse mercado mundializado que se faz presente no diaa-dia de todo cidadão.

\section{Como diz Ortiz ${ }^{1}$}

\begin{abstract}
"na virada do século, percebemos que os homens encontramse interligados, independentemente de suas vontades. Somos todos cidadãos do mundo, mas não no antigo sentido, de cosmopolita, de viagem. Cidadãos mundiais, mesmo quando não nos deslocamos, o que significa dizer que o mundo chegou até nós, penetrou no nosso cotidiano. Curioso."
\end{abstract}

Na verdade este é um processo que vem, ao longo do tempo, tomando formas cada vez mais acentuadas, e, no que diz

${ }^{1}$ ORTIZ, Renato. Mundialização e cultura. 2.ed. São Paulo : Brasiliense, 1994. p. 7. respeito a economia, de maneira a mover as sociedades a se posicionarem de forma a entrar em consonância com esta realidade mundial, da qual não podemos nos eximir, visto que a abertura ou quebra das fronteiras implica, categoricamente, mudanças institucionais político-econômicas e os novos processos de produção.

As empresas com participação ativa neste processo globalizante estão passando por mudanças tecnológicas e organizacionais de grande importância, associadas ao crescimento, cada vez mais efervescente, e ao desenvolvimento das telecomunicações e da disponibilidade informacional, ultrapassando as barreiras da temporalidade e da espacialidade.

Esse aparato informacional é o grande propulsor e possibilitador de um contato cada vez mais próximo e mais íntimo com as idéias, as inovações e os fenômenos que nos circundam e que interferem no fazer individual e coletivo da sociedade.

Dessa forma, pensar a globalização é pensar a integração de países e sua colaboração econômica, política e social. Para tanto é necessário conhecer as realidades de cada país e o fluxo de produção informacional que possibilite uma visão dos avanços e do desenvolvimento pertinentes a cada nação e ao conjunto de todas elas.

As redes de informação têm papel de destaque neste cenário da globalização. No que diz respeito às questões econômicas, Inf.Inf., Londrina, v. 5, n. 2, p. 103-110, jul./dez. 2000 
e não somente a estas, o livre comércio apoiado pela alta tecnologia das telecomunicações impõe uma mudança nas estratégias de gerenciamento que não mais se estabelecem em um único lugar, mas que estão em unidades localizadas em várias partes do mundo, descentralizando assim o desenvolvimento das atividades. É a informação tecnologizada proporcionando a intermediatização das estratégias de gerenciamento e o aumento da competitividade entre países e empresas. É a informação, que neste contexto de profundas mudanças, tem lugar de destaque auxiliando, como afirma Barreto², a

“...monitorar a concorrência, identificar ameaças e oportunidades para as empresas e para os negócios, atualizar e ampliar os conhecimentos sobre gestão, tecnologia e novos processos, estimulando, assim, a cultura da inovação e da qualidade, desenvolvendo ainda competitividade, produtividade e liderança."

Para superar e acompanhar estas transformações, as alianças se projetaram para as nações como alternativa de minimização dos possíveis desencontros e a possibilidade de uma harmonização que pode tornar-se acessível através da integração econômica, política e social.

Essas alianças tomaram formas

\footnotetext{
2 BARRETO, Auta Rojas. Informação empresarial para o Mercosul: a expansão das fronteiras das microempresas. Ciência de Informação, Brasília, v. 25, n. 1, p. 146, jan./abr. 1996.
}

vultuosas quando grandes nações criaram mercados comuns e permitiram a livre negociação de mercadorias, serviços e pessoas.

O livre intercâmbio de bens, moeda, pessoas, instituições e culturas é o princípio básico que norteia o mercado comum. Imbuídas deste conceito as grandes nações desenvolveram modelos para formação de blocos econômicos, desencadeando o surgimento de uma nova ordem mundial e ensejando a que outros países, em diferentes hemisférios, tentassem se aglutinar em prol do livre intercâmbio.

Como constatação dessa evidência temos o Mercado Comum Europeu que, pelo êxito obtido, resultou em exemplo para as demais nações, surgindo também na América do Norte, a Área de Livre Comércio da América - North American Free Trade Area (NAFTA), que reúne Canadá, Estados Unidos e México.

Tornou-se imperioso, portanto, seguir esta nova ordem mundial, onde se abrem cada vez mais mercados comuns tornando este processo irreversível.

Era de se esperar que iniciativas fossem tomadas no sentido de enquadrar a América Latina no mundo dos blocos econômicos. A idéia surgiu do Cone Sul, com Argentina, Brasil, Paraguai e Uruguai, motivados pelo marcante êxito do Mercado Comum Europeu e buscando superar o isolamento, fato gerador do círculo vicioso de 
pobreza e subdesenvolvimento que afligem esta parte do continente americano, deram início, a partir de 1991, à realização de uma série de encontros e estudos objetivando o desenvolvimento de bases para a consolidação do projeto de um mercado comum entre países integrantes do Cone Sul.

Formalizou-se, então, com o Tratado de Assunção, ainda em 1991, a criação do Mercosul - Mercado Comum do Sul - que vem afirmando-se como uma realidade político-comercial e transformando, consideravelmente, os setores produtivos dos países que o integram. Com a abertura do mercado exterior e conseqüentemente o excesso de concentração de empresas e o desemprego em massa, principalmente nos países em desenvolvimento, cresce a competitividade por profissionais mais especializados, onde as empresas associam inovações tecnológicas e automação com mão-de-obra cada vez mais qualificada.

No contexto dos países que formam o Mercosul a integração econômica e política vem-se consolidando cada vez mais. Entretanto, para a concretização efetiva desta aliança faz-se necessária, além dos acordos, convênios e regulamentos celebrados, uma base informacional de sustentação que possibilite as discussões relacionadas à real integração deste bloco regional.

"O fenômeno Mercosul tem o mérito de dar oportunidade aos pa- íses integrantes de olharem para si mesmos, identificando suas potencialidades culturais diferenciadoras, e, [...] conjugar universalidade com diversidade cultural."

Vários são os olhares e várias são as direções desses olhares que perpassam os blocos de mercado comum. Todavia, é no setor informacional que reside, hoje, o grande suporte desenvolvimentista.

A informação representa o meio pelo qual as organizações sincronizam as suas funções, com vistas em uma produção de qualidade dos bens e serviços, atendendo, assim, aos requisitos do mercado consumidor. É a informação fomentando a excelência da qualidade da gestão organizacional, através da mão-de-obra qualificada e adequação dos produtos e serviços às exigências de um mercado de alta competitividade.

A globalização e um mercado altamente competitivo têm levado os profissionais da informação a buscarem uma fatia do mercado onde, a informação, mesmo sendo produto de uma história individual e coletiva, vem tornando-se, cada vez mais, uma parceira indispensável na medida em que uma base informacional é condição precípua para o aumento na produtividade e na melhoria da qualidade dos produtos e serviços, pela rapidez com que se

\footnotetext{
${ }^{3}$ LEAL, Joice Joppert, MALAGUTI, Cyntia. Design e informação no Mercosul. Ciência da Informação, Brasília, v. 25, n. 1, p. 152, jan./abr. 1996.
}

Inf.Inf., Londrina, v. 5, n. 2, p. 103-110, jul./dez. 2000 
conforman às mudanças tecnológicas.

Entretanto, necessário se faz que estejamos alertas para o fato de que a globalização ao mesmo tempo em que alarga e impulsiona a modernização da tecnologia e dos métodos de trabalho, também é provocadora do desemprego e, paradoxalmente, também propiciadora da emergência de novas formas de economias sociais.

Assim, incide sobre os formatos de organização do trabalho coletivo o novo caminho para a superação das dificuldades que emergem. São estes padrões do trabalho coletivo que regem as novas iniciativas sociais. E nesse ambiente é o cooperativismo a vedete das economias sociais emergentes.

A história do cooperativismo vem da Inglaterra, de 1844, através de um pequeno grupo de 28 operários que trabalhavam nos teares das indústrias de tecido. Com o objetivo de minorar suas condições de vida, até então regidas pelo sistema político-econômico vigente, resolveram abrir um armazém que lhes proporcionasse alimentos, roupas e ferramentas de trabalho. Nascia, assim, a primeira cooperativa de consumo da história. ${ }^{4}$ Aliando desenvolvimento econômico à solidariedade e à moral, o grupo tinha plena consciência da importância social do movimento que estava se iniciando.

4 INSTITUTO DO HOMEM. Manual do cooperativismo. São Luís, 1992. p.8. (Estudos e pesquisas, 8 ).
Apesar da pobreza material, o movimento se estendeu por toda a Inglaterra e pelo mundo inteiro, numa demonstração do imenso poder da ajuda mútua.

Nesta ordem social, que é o cooperativismo, passeiam a multicultura, a participação e a autonomia voltada para a igualdade de direitos, das necessidades e valores comuns e da ética.

O trabalho cooperativo, como fonte aglutinadora de pessoas com interesses e problemas comuns, busca na união de seus associados o fortalecimento das medidas e tomadas de decisões em prol da solução desses problemas, que na sua maioria decorrem da globalização e, portanto, de uma alta competitividade no mercado de trabaIho, impulsionando, dessa forma, a procura pelo cooperativismo como uma alternativa de trabalho.

A procura pela formação do trabalho cooperativo tem sido cada vez mais crescente por parte dos profissionais liberais, se levarmos em conta o fato de o coletivo predominar sobre o individual, resultando em grandes ganhos não só para os grupos profissionais como para o usuário ou grupo de usuários destes serviços.

Na era da globalização o cooperativismo, para os profissionais da informação, talvez seja uma alternativa para um mercado exigente e competitivo que cada dia mais cresce, e onde as idéias e as manifestações culturais transitarão livremente entre 
os países, independente de tempo e espaço.

\section{BIBLIOGRAFIA}

ALLEVATO, Sônia Regina. Metodologia de inventário das estatísticas nacionais para o Mercosul. Ciência da informação, Brasília, v. 24, n. 2, p. 249-252, maio/ago. 1995.

ANDRADE DE ECHEGARAY, Maria Auxiliadora, MARTINEZ USERO, José Rangel. Possibilidades para el desarrolo de sistemas de información en el ámbito de Mercosul: comparación con la experiencia europea. 1996.

ARARIPE, Fátima Maria Alencar. A Informação e o profissional bibliotecário no cenário de globalização social. In: CONGRESSO BRASILEIRO DE BIBLIOTECONOMIA E DOCUMENTAÇÃO, 18., 1997, São Luis/Ma. Anais ... São Luis, 1997.

BARRETO, Auta Rojas. Informação empresarial para o Mercosul: a expansão das fronteiras das microempresas. Ciência da informação, Brasília, v. 25, n. 1, p. 144-149, jan./abr. 1996.

BULIK, Linda. Doutrinas da informação no mundo de hoje. São Paulo : Loyola, 1990.

CONNOR, Steven. Cultura pós-moderna: introdução às teorias do contemporâneo. São Paulo : Loyola, 1992.

IANNI, Octavio. A Sociedade global. 2.ed. 
Rio de Janeiro : Civilização Brasileira, 1993.

INSTITUTO DO HOMEM. Manual do cooperativismo. São Luís, 1992. p. 8. (Estudos e pesquisas, 8).

LEAL, Joice Joppert, MALAGUTI, Cyntia. Design e informação no Mercosul. Ciência da Informação, Brasília, v. 25, n. 1, p. 152, jan./abr. 1996.

McCARTHY, Cavan Michael. O Impacto do Mercosul sobre a editoração no Brasil. Ciência da informação, Brasília, v. 26, n. 1, p. 12-19, jan./abr. 1997.

MOURA, Luciano Raizer. Informação: a essência da qualidade. Ciência da informação, Brasília, v.25, n.1, p. 36-42, jan./abr. 1996.

ORTIZ, Renato. Mundialização e cultura. 2.ed. São Paulo : Brasiliense, 1994.

ROCHA, Eliana da Conceição, GOMES, Suely Heinrique de A. Gomes. Gestão da qualidade em unidades de informação. Ciência da informação, Brasília, v. 22, n. 2, p. 142-152, maio./ago. 1993.

SANTOS, Milton et al (org.). Fim de século e globalização: o novo mapa do mundo. 2.ed. São Paulo : Hucitec, 1994.

\section{Fátima Maria Alencar Araripe}

Professora do Departamento de Comunicação Social e Biblioteconomia da UFC. Mestranda em História Social - UFRJ/UFC. Especialista em Teorias da Comunicação e da Imagem - UFRJ/UFC. Especialista em Organização e Administração de Bibliotecas Públicas e Escolares - UFC.

\section{Rossana Coely de Oliveira Moura}

Professora Substituta do Departamento de Comunicação Social e Biblioteconomia da UFC. Especialização em Informática - UFC.

\section{Title}

The Co-operativism in the Information Market of Mercosul: an Alternative

\section{Abstract}

This paper addresses the current scenario of the globalization process as the great propeller of the nations' concerns with the formation of alliances according to economy blocks. It presents globalization as an important factor in unemployment and points out co-operativism as a job alternative in the information market. In that context, it emphasizes the importance of informational bases as a basic assumption in the adequacy of products and services that assist this new social order.

\section{Keywords}

Globalization; Information; Mercosul; Cooperativism. 


\section{Titulo}

Cooperativismo en el Mercado Informacional del Mercosur: una Alternativa

\section{Resumen}

El texto da énfasis al escenario actual del proceso de globalización como el gran propulsor del desencadenamiento de las preocupaciones de las naciones en formar alianzas por bloques económicos. Presenta la globalización como un coadyuvante del factor desempleo y señala el cooperativismo como una alternativa de trabajo en el mercado de información. En ese contexto, resalta la importancia de las bases informacionales como presupuesto básico para la adecuación de los productos y servicios que atendan a esa nueva orden social.

\section{Palabras-Clave}

Globalización; Información; Mercosur; Cooperativismo

Artigo recebido em: 30/04/98 